\title{
Fishing Revenue, Productivity and Product Choice in the Alaskan Pollock Fishery
}

\author{
Catherine J. Morrison Paul • Marcelo de O. Torres • \\ Ronald G. Felthoven
}

Accepted: 12 May 2009 / Published online: 21 June 2009

(C) The Author(s) 2009. This article is published with open access at Springerlink.com

\begin{abstract}
A key element in evaluating fishery management strategies is examining their effects on the economic performance of fishery participants, yet nearly all empirical studies of fisheries focus exclusively on the amount of fish harvested. The economic benefits derived from fish stocks involve the amount of revenue generated from fish processing, which is linked to both the way fish are harvested and the products produced from the fish. In this study we econometrically estimate a flexible revenue function for catcher-processor vessels operating in the Alaskan pollock fishery, recognizing potential endogeneity and a variety of fishing inputs and conditions. We find significant own-price supply responses and product substitutability, and enhanced revenues from increased fishing days and tow duration after a regulatory change introduced property rights through a new fishing cooperative. We also find significant growth in economic productivity, or higher revenues over time after controlling for observed productive factors and price changes, which exceeds that attributable to increased harvest. These patterns suggest that the move to rights-based management has contributed significantly to economic performance in the pollock fishery.
\end{abstract}

Keywords Fisheries $\cdot$ Revenue function $\cdot$ Productivity $\cdot$ Environmental factors

C. J. M. Paul (两)

Department of Agricultural and Resource Economics and the Giannini Foundation, University of California, Davis, One Shields Avenue, Davis, CA 95616, USA

e-mail: cjmpaul@primal.ucdavis.edu

M. O. Torres

Department of Economics, Catholic University of Brasília, Brasília, DF 70190-045, Brazil

e-mail: torres@primal.ucdavis.edu

R. G. Felthoven

U.S. National Marine Fisheries Service, Alaska Fisheries Science Center,

7600 Sand Point Way NE, Seattle, WA 98115, USA

e-mail: ron.felthoven@noaa.gov 


\section{Introduction}

It has long been recognized that common property fishery management and many regulations designed to alleviate resulting biological and economic pressures have negative consequences on the economic performance of fisheries. To maintain biological viability, regulations typically restrict the exploitation of fish stocks using direct output or input constraints. Such restrictions, however, fail to curb many repercussions of common-property management (such as over-capitalization), tend to encourage "input stuffing," 1 and reduce harvesting efficiency, which depresses profits for fishermen and paradoxically may exacerbate problems the restrictions were intended to assuage.

The vast literature on the benefits of moving away from this type of management shows that value from the resource can be augmented by allocating access privileges and introducing more rational incentives. However, little work has focused on how resulting innovations in processing as well as harvesting can increase the benefits derived from the biological stock. In particular, the form of fishery management influences the rate at which the fishery is prosecuted, and in turn which processed products will (or can) be produced from the catch. Economic gains to fishermen from eliminating a race for fish can thus be achieved by improving processors' abilities to control the rate at which fish enter the processing chain, and to adapt their product choices in response to prices or other market, regulatory or environmental factors.

In this article we model and measure how revenues have been impacted by fishing and processing choices made by catcher-processor vessels operating in the Bering Sea and Aleutian Islands (BSAI) pollock fishery. This fishery is one of the largest in the world, with annual catch levels exceeding 1.0 million metric tons (by all fishery participants) and accounting for over $20 \%$ of total US fishery landings (NMFS 2007). It is also recognized as one of the bestmanaged fisheries in the world due to the large and stable population and annual harvests. We analyze production in this fishery over a time period (1994-2004) when management switched from regulated open access to a quota-based regime due to the 1998 American Fisheries Act (AFA). This change allows us to evaluate the economic impacts of two distinct institutional settings through a natural experiment (Frech 1976; Brunt 2007; Grafton et al. 2000; Rausser et al. 2008).

Our analysis is based on a (dual) revenue function model, consistent with behavior recognized by fishery economists in the literature, ${ }^{2}$ but takes a somewhat different perspective than most existing studies. For example, most studies focus on capacity utilization or examine whether technological harvesting interactions exist among species to infer how to best manage stocks (either individually or as a joint complex). ${ }^{3}$ Some attention has also been paid to product choice, taking the harvested fish as a given intermediate input. ${ }^{4}$ However, we know of no studies that recognize joint decisions of catcher-processors as we do in this study.

\footnotetext{
${ }^{1}$ Input stuffing is a process by which fishermen increase their use of unregulated inputs to maintain or increase fishing power (in order to increase catch share, or the rate at which they catch fish) when regulations on other inputs or catch levels are intensified.

2 The relevance of output or revenue maximization for fisheries has been recognized by researchers such as, Squires (1987), Kirkley et al. (1995), Weninger and Just (1997), and Weninger (2001). A useful survey of the application of dual models to fisheries is provided in Jensen (2002). Note also that output and revenue data are more readily available than input price data required for cost- or profit-based dual economic models.

${ }^{3}$ See Kirkley and Strand (1988), Squires and Kirkley (1991), Segerson and Squires (1993, 1995), Thunberg et al. (1995), Diop and Kazmierczak (1996), and Alam et al. (2002).

${ }^{4}$ See Asche and Hannesson (2002).
} 
More specifically, we model the harvesting and processing technology of catcher-processors in the BSAI pollock fishery, with a focus on their product choices and productivity over the sample period. The flexible revenue function we use for our analysis relaxes the common assumptions in the literature of a single composite input and separability of this input from the outputs, which allows consideration of the interactions among the multiple species and produced products, and the inputs used for production. In particular, we account for capital heterogeneity by including vessel-specific measures of horsepower, length, and gross tonnage, and for fishing strategies by including measures of tow numbers and duration. In addition, we incorporate fishing conditions such as climate that can shift (and twist) the relationships among inputs and outputs, and product seasonality by distinguishing winter and summer seasons and using dummy variables to account for seasonal or technical differences in the product choice set. In contrast to previous studies, we also consider whether three stage least squares (3SLS) rather than standard seemingly unrelated regression (SUR) techniques should be used to estimate our model, due to potential issues from endogeneity of fishing practices.

Our results show that product supply is significantly responsive to product prices, as well as to inputs and external factors not typically included in revenue models. In particular, modifications to fishing strategies afforded by the AFA have augmented revenues by contributing to the production of deep-skin (higher quality) fillets and roe. Further, increasing prices of roe and deep-skin fillets have significantly increased the shadow values of fishing strategies and other inputs - especially towing duration but also crew and vessel power. These patterns are consistent with the industry perception that the change to a quota-based fishery has reduced the pace of fishing and processing effort, permitting greater flexibility and facilitating lucrative product choice and quality changes.

We also find a significant residual upward trend in revenues that indicates increasing economic productivity, and is substantially greater in the post-AFA period. This productivity growth is strongest over the whole period for fillet products but increasing the most rapidly (and to the highest level in terms of its marginal contribution to revenue) for roe.

\section{Methodological Framework and Variables}

A revenue function represents the maximum revenue a firm (vessel) may attain given prevailing output prices, observed input levels, and existing production (fishing and processing) conditions and technology. Generally, this function takes the form $R(\mathbf{P}, \mathbf{Z}, \mathbf{T})$, where $\mathbf{P}$ is a vector of $M$ output prices, ${ }^{5} \mathbf{Z}$ a vector of $L$ input levels, and $\mathbf{T}$ a vector of $J$ (fishing) conditions, such as weather or technological factors. Such a function must satisfy regularity conditions for the $\mathbf{P}$ and $\mathbf{Z}$ variables for the function to be a relevant representation of technology and product choice. In particular, $R$ should be linearly homogeneous in $\mathbf{P}$ (if all output prices increase by the same proportion so does revenue; $\sum_{m} \partial \ln R / \partial \ln P_{m}=1$ ), and non-decreasing in $\mathbf{P}$ and $\mathbf{Z}$ (higher output prices or input levels will not decrease revenue; $\partial R / \partial P_{m} \geq 0, \partial R / \partial Z_{l} \geq 0$ ). Further, by Hotelling's Lemma $Y_{m}=\partial R / \partial P_{m}$ is the supply equation for $Y_{m}$ (where $Y$ denotes output and $\mathrm{m}$ the specific product), so $R$ is convex in $\mathbf{P}$ (own-price supply responses are nonnegative; $\left.\partial^{2} R / \partial P_{m}^{2}=\partial Y_{m} / \partial P_{m} \geq 0\right)$. There is, however, no condition about cross-effects with more than two outputs; if $\partial^{2} R / \partial P_{m} \partial P_{n}=\partial Y_{m} / \partial P_{n} \geq$ or $\leq 0, Y_{m}$ and $Y_{n}$ are, respectively, complements or substitutes.

5 This requires the assumption that "firms" are output price takers, which is reasonable for individual vessels. 
To empirically implement the revenue function we must first specify its arguments for our application. Our data are made up of weekly observations for 30 catcher-processors that operated with trawl gear in the BSAI pollock fishery during 1994-2004. ${ }^{6}$ To facilitate analysis of trends in economic performance (revenue or economic productivity) we aggregated these data to the seasonal level (where " $\mathrm{A}$ " is the winter and " $\mathrm{B}$ " is the summer season, as traditionally distinguished for this fishery) to reflect different products available in the vessels' choice sets. $^{7}$

Alaskan pollock is a pelagic whitefish that is amenable to a range of retail products, such as fish and chips, fish sandwiches, and frozen food products (utilizing the fillet portion of the pollock). The catcher-processor fleet generates nearly $\$ 300$ million in annual pollock revenue (Hiatt 2007) from production of three main products: fillets (regular and higher quality "deep-skin"), surimi, and roe. Surimi is a fish paste used to make products such as imitation crabmeat, and pollock roe is a high-value product processed almost exclusively during the winter/spring.

The vessels within the catcher-processor fleet fish with similar (trawl) gear and are comparably sized, although some are equipped with processing facilities to produce surimi and others primarily produce fillets. ${ }^{8}$ The average vessel is close to 300 feet long, has a volume of 1,800 gross registered tons, and operates at nearly 6,000 horsepower. Most vessels target pollock exclusively, but because flatfish species commingle with pollock at certain depths and areas they are also caught and sold. ${ }^{9}$

The (endogenous) choice variables in our model are the primary products produced in this fishery: regular and deep-skin fillets, surimi, and roe, with the composition depending on the relative prices and season. Once these products are taken the remainder of the pollock is used for mince or meal and oil (Fell 2006), which are thus leftover or ancillary products. ${ }^{10}$ The products from other species (flatfish) that are produced are also secondary to the targeted pollock products. The products for our model therefore are surimi $(S)$, roe $(R)$, regular fillets $(F)$, deep-skin fillets $(D)$, other-pollock products $(O)$, and nonpollock products $(N)$, with prices $P_{m}$ in the $\mathbf{P}$ vector corresponding to output quantities $Y_{m}(m=S, R, F, D, O, N)$.

Dummy variables are used to recognize the fact that roe is produced almost exclusively in the A season (after spawning occurs in the B season), and that some vessels never produce surimi and therefore can be assumed not to have the technological potential to do so. Specifically, the supply of products $Y_{R}$ and $Y_{S}$ depend on prices represented as $P_{R}^{*}=$ $P_{R}\left(1+D_{R} \times \beta_{R}\right)$ and $P_{S}^{*}=P_{S}\left(1+D_{S} \times \beta_{S}\right)$, where $D_{R}$ and $D_{S}$ are dummy variables for when production of roe or surimi is infeasible and $\beta_{R}$ and $\beta_{S}$ are estimated parameters

\footnotetext{
6 More specifically, as discussed further in Felthoven and Paul (2004), the data were obtained from the US National Marine Fisheries Service federal observer program, weekly processing reports, federal vessel and ADF\&G registration files, US Coast Guard data, and the 2004 NMFS stock assessment and fishery evaluation report.

7 In particular, roe is the primary focus in winter, but roe is infrequently present in pollock in the summer and therefore typically not a viable product in the B season.

8 Since the AFA was implemented and the fishery was rationalized, most boats are now equipped to produce either product and may switch-out processing lines in response to which product price is higher.

9 A distinct allocation of flatfish is made to the pollock fishermen.

10 Federal "full retention and utilization" requirements mandate that processors may not dump fish carcasses overboard after extracting roe and flesh portions used in fillets and surimi. Therefore, secondary products, such as meal, mince and oil must be produced regardless of price signals observed.
} 
reflecting the "perceived" price (or shift in the corresponding supply equation) for those observations. ${ }^{11}$

The input vector $\mathbf{Z}$ includes (weekly) crew size, $Z_{C}$, days fished, $Z_{D A}$, and vessel characteristics (gross tons, $Z_{G}$, length, $Z_{L}$, and horsepower, $Z_{H}$ ). ${ }^{12}$ This input breakdown represents specific components of fishing "effort" rather than combining them into a single composite input, or focusing just on harvesting or on processing from the raw fish (as an intermediate output), as in the existing literature. Note also that inclusion of the (time-invariant) boat-specific characteristics precludes the need to include fixed effects representing vessel heterogeneity, as vessel differences are more specifically taken into account by these variables.

The $\mathbf{Z}$ vector also includes towing duration $\left(Z_{D U}\right)^{13}$ and number of tows $\left(Z_{T O}\right)$ as indicators of fishing methods, both of which have been affected by regulatory changes and reflect the effectiveness of effort. ${ }^{14} Z_{D U}$ distinguishes actual towing time from total time at sea, reflecting effort applied to obtain the observed catch rather than time spent searching or transporting. Higher $Z_{T O}$ implies smaller or less-full nets, ceteris paribus, suggesting higher quality product due to decreased bruising of fish. ${ }^{15}$

The fishing conditions in the $\mathbf{T}$ vector include a time trend proxying technical change, $t$, and three measures of environmental conditions (weather or climate). $T_{N P I}$ is a wind and storm indicator - the North Pacific Index measuring the anomalous atmospheric circulation of the North Pacific from spring into summer. Higher values correspond to a lower tendency for stormy weather and positive summer sea surface temperature anomalies. $T_{S W}$ and $T_{S A}$ are temperature indicators - surface air temperature measures for the winter (December-March) and annually (January-December), calculated as deviations from a 1950-2000 base. ${ }^{16}$

Regulatory and stock factors also have impacts on fishing revenues. In particular, the passage of the AFA in 1998, which aimed at rationalizing the BSAI pollock fishery, was a key regulatory change for this fishery. The main components of the Act involved identifying vessels and shore-side processors eligible to participate in harvesting and processing, buying back nine catcher-processor vessels, allocating about $10 \%$ more of the TAC to the inshore sector, and authorizing the formation of harvesting and fishing cooperatives among the remaining participants. The participants were assigned quota shares based on their

\footnotetext{
11 We will use $\mathrm{P}^{*}$ to represent the prices of all products for notational consistency, but $\mathrm{P}^{*}$ is the same as $\mathrm{P}$ for all products other than roe and surimi.

12 The use of gross tons as a size indicator is typical in the literature on fishery production. We also have data on net tons, which differs from gross tons by the amount of unusable space occupied by, for example, machinery. This difference, which varies significantly across boats, may provide an indicator of vesselspecific processor technology, which we recognize by including the ratio of gross to net tons as an instrument for estimation. Note also that negligible substantive changes resulted from using net rather than gross tons as a capital size variable.

13 This is the actual number of hours that the vessel's trawl gear was in the water towing for fish.

14 This is the number of times a vessel puts the net in the water, fills it to some extent, and brings it out of the water.

15 The slower fishing pace associated with more tows per quantity of catch allows a higher processing product recovery rate and ability to change product forms, and thus increased resource value. Greater towing duration may also imply increased time spent doing test tows to search for the best fish for the products, with quality implications.

$16 T_{N P I}$ and $T_{S W}$ are sometimes measured as negative values since they are calculated as deviations from a base. These variables were scaled up so that they are always $>0$, which does not affect the variables' significance or sign of the derivative but does affect the magnitude of the average elasticities (because otherwise the sign of the elasticities depends on whether the measure is positive or negative). Note also that we also have data on ice cover but found that this variable was very closely correlated with $T_{S W}$, so we only included the latter.
} 
historical catch, ${ }^{17}$ thereby changing the nature of production and economic performance in the fishery. For example, analysis of harvesting productivity by Felthoven et al. (2007) found that regulatory effects of the AFA have been embodied in modifications of fishing practices, such as fishing pace and product quality, that likely affect products produced and revenues achieved.

These results imply that the effects of the AFA are embodied in endogenous changes of our days, tows and duration variables. ${ }^{18}$ We therefore use a dummy variable for the imposition of the AFA, equal to one for post-1998 catches, as an instrument for these variables for our alternative 3SLS estimation model. We also include as instruments other variables found by Felthoven et al. (2007) to be indirectly related to regulatory changes, including metric tons of salmon and herring bycatch (proxying regulations on prohibited species that have affected the ability of fishermen to fish where they want), and number of crab bycatch (proxying regulations on bottom-trawling that have affected how fishermen can fish). An estimate of the metric tons of pollock stock ${ }^{19}$ (which empirically has been found to be more closely related to the amount of pollock available to the fleet than to fishing productivity), ${ }^{20}$ a ratio of the two fillet prices (as an indicator of the price premium for fish quality), and a ratio of vessel gross to net tons (as an indicator of technology) were also used as instruments. ${ }^{21}$

\section{Empirical Implementation}

The functional form we assume for estimation is a fully flexible generalized Leontief, which recognizes cross-effects or substitution/interaction patterns among all arguments of the function. This function is written as:

$$
\begin{aligned}
& R_{\mathrm{it}}= R_{\mathrm{it}}\left(\mathbf{P}_{\mathrm{it}}^{*}, \mathbf{Z}_{\mathrm{it}}, \mathbf{T}_{\mathrm{it}}\right) \equiv \sum_{m} \sum_{n} \alpha_{m n} P_{m \mathrm{it}}^{* .5} P_{n \mathrm{it}}^{* .5}+\sum_{m} \sum_{l} \delta_{m l} P_{m \mathrm{it}}^{*} Z_{l \mathrm{it}} \\
&+\sum_{m} \sum_{j} \delta_{m j} P_{m \mathrm{it}}^{*} T_{j \mathrm{it}}+\sum_{m} P_{m \mathrm{it}}^{*}\left(\sum_{l} \sum_{q} \delta_{l q} Z_{l \mathrm{it}} Z_{q \mathrm{it}}+\sum_{j} \sum_{k} \delta_{j k} T_{j \mathrm{it}} T_{k \mathrm{it}}\right. \\
&\left.+\sum_{l} \sum_{j} \delta_{l j} Z_{l \mathrm{it}} T_{j \mathrm{it}}\right)
\end{aligned}
$$

\footnotetext{
${ }^{17}$ Strictly speaking their allocations went to the catcher-processor cooperative, which then made sub-allocations based on historic catch and facilitated trades among cooperative members.

18 In particular, when these variables (days, hauls and tows) are included in production analysis, as in Felthoven et al. (2007), parameters and elasticities for a dummy variable reflecting imposition of the AFA become insignificant or the wrong sign, indicating that the impact of the AFA is embodied in, or proxied by, these variables.

19 This variable, measured as metric tons of pollock (3-year-old or more) in the Eastern Bering Sea, is not under control of individual boats or boat captains but does depend on the overall fishing effort of the fleet.

20 This stock variable was found invariably (through alternative specifications) to have an insignificant direct effect on harvesting productivity, potentially because it affects regulatory restrictions rather than indicating abundance that affects the effectiveness of fishing effort. We also tried using ratios of the prices of deep-skin (higher quality) to regular pollock fillets to proxy quality premiums, and of gross to net tons to proxy on-board processing technology, as instruments, but inclusion of these factors negligibly affected the estimates.

${ }^{21}$ Although relying on all these variables over-identifies the model, for our presented estimates we included them all because the results were negligibly affected by variations in the instrument specification.
} 
where $m, n$ denote output prices, $l, q$ input levels and $j, k$ fishing conditions, and the effective or perceived price $P_{m}^{*}$ for product $m$ is $P_{m}\left(1+D_{m} \times \beta_{m}\right)$ for roe and surimi and $P_{m}$ for the other product types.

The estimating equations for this model include Eq. 1 plus supply equations for the primary products for which price responsiveness is expected-roe, surimi and the two types of fillets (with other-pollock and flatfish products recognized to be ancillary or secondary products). ${ }^{22}$ These equations are written as:

$$
\begin{aligned}
Y_{m i \mathrm{t}}= & \frac{\partial R_{\mathrm{it}}\left(\mathbf{P}_{\mathrm{it}}^{*}, \mathbf{Z}_{\mathrm{it}}, \mathbf{T}_{\mathrm{it}}\right)}{\partial P_{m \mathrm{it}}^{*}} \equiv \sum_{n} \alpha_{m n} P_{n \mathrm{it}}^{* .5} / P_{m \mathrm{it}}^{* .5}+\sum_{l} \delta_{m l} Z_{l \mathrm{it}}+\sum_{j} \delta_{m j} T_{j \mathrm{it}} \\
& +\sum_{l} \sum_{q} \delta_{l q} Z_{l \mathrm{it}} Z_{q \mathrm{it}}+\sum_{j} \sum_{k} \delta_{j k} T_{j \mathrm{it}} T_{k \mathrm{it}}+\sum_{l} \sum_{j} \delta_{l j} Z_{l \mathrm{it}} T_{j \mathrm{it}}, \\
& m=(R, F, D, S),
\end{aligned}
$$

We estimated our system of five equations from (1) and (2) by SUR techniques, which increases econometric efficiency for equation systems whose errors may be correlated. SUR has been the standard estimation method in the literature when fishing inputs are assumed essentially fixed for the period under study (Kirkley and Strand 1988; Squires and Kirkley 1991; Segerson and Squires 1993; Thunberg et al. 1995; Campbell and Nicholl 1994; Squires and Kirkley 1991; Diop and Kazmierczak 1996; Asche and Hannesson 2002). It can also be appropriate when variables are potentially endogenous (such as days, or the composite effort variable constructed in these studies as a product of $Z_{G}$ and days), as the revenue function represents the highest returns obtainable by optimal product choice from a given observed input bundle and technology. ${ }^{23}$ Further, choices, such as the number of fishing days may be driven at least indirectly by exogenous factors, such as unobserved fishing and boat conditions (e.g., fish location or engine problems).

However, even if boat characteristics and crew levels in our $\mathbf{Z}$ vector are considered fixed in a season (and fishing conditions, such as weather in our $\mathbf{T}$ vector are clearly exogenous), fishing practices, such as days fished, number of tows, and towing duration remain primarily under the control of the vessel skipper. This raises endogeneity questions for econometric implementation that have not been addressed in the fisheries literature, which we investigated through our alternative 3SLS estimating model. The resulting estimates were very robust both between SUR and 3SLS estimation and for different combinations of instruments. We report the SUR results both because the empirical implications were invariant to 3SLS estimation, and because a Hausman test indicated that endogeneity was not an issue for this application. ${ }^{24}$

Our flexible functional form allows both first-order productive relationships and secondorder interactions among inputs and output prices to be represented rather than assuming homothetic or fixed-proportion technologies. We used our estimated parameters to compute

\footnotetext{
22 This assumption was empirically supported by estimates of supply responses that were insignificantly different from zero. In fact, as discussed below, the estimate of $\partial R / \partial P_{m}$ for non-pollock products was robustly but insignificantly negative, suggesting that boats that catch flatfish do not generate as many revenues as those that produce more of the target fish stock (pollock).

${ }^{23}$ For example, although most of these studies are based on a composite input level, Asche and Hannesson (2002) model product choice with the raw fish "produced" from fishing (harvesting) inputs as the fish processing input.

24 The test is essentially a Wald test on the differences in SUR and 3SLQ estimate and variance matrices. The calculated value for the test is 12.20, which with 6 degrees of freedom (rank of the difference in the variance matrices) and a $95 \%$ critical value of 12.59 does not suggest that the endogeneity of duration, days and tows variables is an issue for this application.
} 
the first- and second-order elasticities of the revenue function, which are proportional measures of the first and second derivatives reflecting the determinants of revenues and productivity, and their underlying cross-effects, for the BSAI pollock fishery.

Specifically, the first-order elasticities are the revenue elasticities with respect to the components of the $\mathbf{P}, \mathbf{Z}$, and $\mathbf{T}$ vectors indicating the forces underlying revenue changes. The product price elasticities $\varepsilon_{R} P_{m}^{*}=\frac{\partial \ln R}{\partial \ln P_{m}^{*}}=\frac{\partial R}{\partial P_{m}^{*}} \times \frac{P_{m}^{*}}{R}=\frac{P_{m}^{*} Y_{m}}{R}$ reflect the marginal revenue share of product $m$, which must be positive for the products exhibiting supply responsiveness. The input elasticities $\varepsilon_{R Z_{l}}=\frac{\partial \ln R}{\partial \ln Z_{l}}=\frac{\partial R}{\partial Z_{l}} \times \frac{Z_{l}}{R}=\frac{W_{l} Z_{l}}{R}$, where $W_{l}$ is the marginal shadow value of input $l$ in terms of its contribution to revenue (Squires and Kirkley 1991; Segerson and Squires 1993), reflect the corresponding shadow shares that will be positive for productive inputs. The elasticities with respect to the $\mathbf{T}$ factors, $\varepsilon_{R T j}=\frac{\partial \ln R}{\partial \ln T_{j}}=\frac{\partial R}{\partial T_{j}} \times \frac{T_{j}}{R}=\frac{W_{j} T_{j}}{R}$, similarly reflect the revenue contribution of $T_{j}$ and may be either positive or negative. For example, (economic) productivity growth, in terms of the trend in revenues not explained by other productive factors in the model, is expressed as $\varepsilon_{R t}=\frac{\partial \ln R}{\partial t}=\frac{\partial R}{\partial t} / R$, so a positive value indicates economic productivity growth but a negative value is possible.

The second-order elasticities with respect to the components of $\mathbf{P} *$ represent the ownand cross-supply responses for fish products, where $\varepsilon_{y_{m} P_{n}^{*}}=\frac{\partial^{2} \ln R}{\partial \ln P_{m}^{*} \partial \ln P_{n}^{*}}=\frac{\partial \ln Y_{m}}{\partial \ln P_{n}^{*}}$ will be non-negative for $m=n$, and will reflect complementarity or substitutability if positive or negative (respectively) for $m \neq n(m, n=R, F, D, S)$. The supply impacts of other variables are represented by second-order elasticities of $Y_{m}$ choice with respect to the $\mathbf{Z}$ and T variables, such as $\varepsilon_{Y_{m}} Z_{l}=\frac{\partial \ln Y_{m}}{\partial \ln Z_{l}}$, which indicate, for example for $m=R$ and $l=C$, the marginal change in roe production from hiring an additional crew member.

Second-order elasticities may also be computed to represent the impacts on the input shadow values $W_{l}$ of changes in the components of $\mathbf{P}, \mathbf{Z}$ and $\mathbf{T}$ (Squires and Kirkley 1991; Segerson and Squires 1993). Such elasticities, expressed as $\varepsilon_{W_{l} P_{m}}=\frac{\partial \ln W_{l}}{\partial \ln P_{m}}$, indicate for example for $l=C$ and $m=R$ how the shadow value of crew is affected by the price of roe (which will be symmetric with and thus the same sign as $\varepsilon_{Y_{m}} Z_{l}=\frac{\partial \ln Y_{m}}{\partial \ln Z_{l}}$ by Young's theorem). Similarly, $\varepsilon_{W_{l}} Z_{q l}=\frac{\partial \ln W_{l}}{\partial \ln Z_{q}}$, where $q=H$, shows the impact on the crew shadow value of an increase in vessel power.

\section{The Results}

\subsection{The Estimation and Measures}

The parameter estimates from our SUR model are presented in Table 5 (in Appendix). The overall estimates were very robust to sensitivity tests, such as substituting net for gross tons as an argument of the revenue function, ${ }^{25}$ as well as to alternative estimating models ${ }^{26}$ and instrument specifications. Further, the $R^{2}$ s for the equations suggest a good representation of the technology and supply behavior; for the revenue Eq. 1 the $R^{2}$ is 0.873 and for the supply Eq. 2 they are 0.796 for $Y_{R}, 0.715$ for $Y_{S}, 0.512$ for $Y_{B}$, and 0.500 for $Y_{D}$.

\footnotetext{
25 It is worth noting, however, that some results differed slightly when a time trend was not included. In particular, the first order elasticity for $Y_{O}$ was significant, that for $T_{N P I}$ was insignificant, and that for $T_{S A}$ was the reverse sign (likely because the cross term between $T_{S A}$ and $t$ is significantly negative so the $T_{S A}$ revenue effect has a trend).

26 The estimates were also robust to including the "residual" $Y_{O}$ and $Y_{N}$ product categories as primary products, by including their supply equations for estimation. However, as both industry knowledge and empirical results suggest that they are usually residual categories, we did not estimate these equations.
} 
Table 1 First-order revenue contributions (elasticities)

\begin{tabular}{|c|c|c|c|c|c|c|c|c|}
\hline \multicolumn{3}{|l|}{ Products } & \multicolumn{3}{|l|}{$\mathbf{Z}$ factors } & \multicolumn{3}{|l|}{$\mathbf{T}$ factors } \\
\hline & Estimate & $t$-Stat & & Estimate & $t$-Stat & & Estimate & $t$-Stat \\
\hline \multicolumn{9}{|c|}{ Full sample } \\
\hline$\varepsilon_{R, P_{R}^{*}}$ & 0.251 & 9.80 & $\varepsilon_{R, Z_{c}}$ & 0.520 & 7.30 & $\varepsilon_{R, T_{N P I}}$ & 0.324 & 6.50 \\
\hline$\varepsilon_{R, P_{F}^{*}}$ & 0.094 & 11.21 & $\varepsilon_{R, Z_{H}}$ & 0.456 & 6.07 & $\varepsilon_{R, T_{S W}}$ & 0.044 & 0.15 \\
\hline$\varepsilon_{R, P_{D}^{*}}$ & 0.176 & 14.15 & $\varepsilon_{R, Z_{L}}$ & -0.560 & -5.24 & $\varepsilon_{R, T_{S A}}$ & -0.09 & -1.75 \\
\hline$\varepsilon_{R, P_{S}^{*}}$ & 0.268 & 16.62 & $\varepsilon_{R, Z_{G}}$ & 0.235 & 4.35 & $\varepsilon_{R, t}$ & 0.088 & 16.01 \\
\hline$\varepsilon_{R, P_{O}^{*}}$ & 0.035 & 1.68 & $\varepsilon_{R, Z_{D A}}$ & 0.427 & 4.34 & & & \\
\hline$\varepsilon_{R, P_{N}^{*}}$ & 0.089 & 4.32 & $\varepsilon_{R, Z_{T O}}$ & 0.032 & 0.04 & & & \\
\hline & & & Pre-AFA & 0.136 & 2.55 & & & \\
\hline$\varepsilon_{R, P_{R}^{*}}$ & 0.264 & 8.83 & $\varepsilon_{R, Z_{c}}$ & 0.549 & 5.52 & $\varepsilon_{R, T_{N P I}}$ & 0.406 & 4.18 \\
\hline$\varepsilon_{R, P_{F}^{*}}$ & 0.058 & 4.87 & $\varepsilon_{R, Z_{H}}$ & 0.420 & 4.06 & $\varepsilon_{R, T_{S W}}$ & -0.010 & -0.21 \\
\hline$\varepsilon_{R, P_{D}^{*}}$ & 0.179 & 8.97 & $\varepsilon_{R, Z_{L}}$ & -0.595 & -3.52 & $\varepsilon_{R, T_{S A}}$ & 0.043 & 0.39 \\
\hline$\varepsilon_{R, P_{S}^{*}}$ & 0.329 & 11.17 & $\varepsilon_{R, Z_{G}}$ & 0.414 & 5.04 & $\varepsilon_{R, t}$ & 0.069 & 3.84 \\
\hline$\varepsilon_{R, P_{O}^{*}}$ & -0.015 & -0.41 & $\varepsilon_{R, Z_{D A}}$ & 0.692 & 5.09 & & & \\
\hline$\varepsilon_{R, P_{N}^{*}}$ & 0.137 & 4.23 & $\varepsilon_{R, Z_{T O}}$ & -0.221 & -1.99 & & & \\
\hline & & & ${ }^{\varepsilon} R, Z_{D U}$ & 0.210 & 2.56 & & & \\
\hline \multicolumn{9}{|l|}{ Post-AFA } \\
\hline${ }^{\varepsilon} \varepsilon_{R, P_{R}^{*}}$ & 0.302 & 16.83 & $\varepsilon_{R, Z_{c}}$ & 0.539 & 6.71 & $\varepsilon_{R, T_{N P I}}$ & 0.262 & 6.97 \\
\hline$\varepsilon_{R, P_{F}^{*}}$ & 0.127 & 18.09 & $\varepsilon_{R, Z_{H}}$ & 0.526 & 6.89 & $\varepsilon_{R, T_{S W}}$ & 0.015 & 0.62 \\
\hline$\varepsilon_{R, P_{D}^{*}}$ & 0.187 & 20.88 & $\varepsilon_{R, Z_{L}}$ & -0.572 & -4.65 & $\varepsilon_{R, T_{S A}}$ & -0.214 & -2.40 \\
\hline$\varepsilon_{R, P_{S}^{*}}$ & 0.236 & 26.76 & $\varepsilon_{R, Z_{G}}$ & 0.091 & 1.54 & $\varepsilon_{R, t}$ & 0.106 & 7.04 \\
\hline$\varepsilon_{R, P_{O}^{*}}$ & 0.100 & 6.73 & $\varepsilon_{R, Z_{D A}}$ & 0.216 & 1.66 & & & \\
\hline \multirow[t]{2}{*}{$\varepsilon_{R, P_{N}^{*}}$} & 0.067 & 4.11 & $\varepsilon_{R, Z_{T O}}$ & 0.205 & 1.88 & & & \\
\hline & & & $\varepsilon_{R, Z_{D U}}$ & 0.082 & 1.29 & & & \\
\hline
\end{tabular}

For our flexible functional form the parameter estimates do not individually provide much intuitive information, but are combined into the elasticity measures that better convey the relationships of interest. Our estimated first- and second-order elasticities, evaluated at the arithmetic mean of the data with the standard errors computed by the delta method, ${ }^{27}$ are presented in Tables 1, 2, 3 and 4. To capture differences after the AFA, in Table 1 we present the results broken out into pre- and post-AFA periods as well as for the whole time period. In Tables 2, 3 and 4 we present only the results for the entire period to keep the tables manageable, but will comment on any substantive variability in the magnitudes of the measures for the two time periods.

The first-order elasticities showing the marginal revenue contributions (percentage change in revenue from a percentage change in the factor) of the $\mathbf{P}, \mathbf{Z}$ and $\mathbf{T}$ components are presented in Table 1, with the elasticities that are significantly different from 0 at a $5 \%$ level in bold type. The first-order elasticities for the primary (choice) products $Y_{R}, Y_{F}, Y_{D}$, and $Y_{S}$ are all positive and statistically significant. Surimi comprises the largest marginal revenue contribution or "share" at 0.268 on average across all boats and time periods (about 27\%),

27 The delta method, a generalization of the Central Limit Theorem, is derived by Taylor series approximations. It is useful when one is interested in a function of a random variable rather than the random variable itself (See Gallant and Holly 1980). We implement the delta method using TSP, which uses the parameter estimates from our model and their corresponding variance covariance matrix to evaluate the elasticities at average values of the inputs. 
Table 2 Own- and cross-supply elasticities

\begin{tabular}{|c|c|c|c|c|c|c|c|c|}
\hline \multicolumn{9}{|c|}{ Primary Product } \\
\hline$m$ & $\varepsilon_{Y_{R} P_{m}^{*}}$ & $t$-Stat & $\varepsilon_{Y_{F}, P_{m}^{*}}$ & $t$-Stat & $\varepsilon_{Y_{D}, P_{m}^{*}}$ & $t$-Stat & $\varepsilon_{Y_{S,} P_{m}^{*}}$ & $t$-Stat \\
\hline$R$ & 0.705 & 8.91 & -0.531 & -6.83 & -0.222 & -4.16 & -0.060 & -2.46 \\
\hline$F$ & -0.304 & -6.83 & 1.997 & 4.12 & -1.144 & -4.64 & -0.175 & -2.02 \\
\hline$D$ & -0.223 & -4.16 & -2.010 & -4.63 & 1.560 & 4.10 & -0.703 & -3.33 \\
\hline$S$ & -0.088 & -2.46 & -0.452 & -2.01 & -1.040 & -3.32 & 1.030 & 4.04 \\
\hline$O$ & -0.098 & -2.15 & 0.956 & 5.02 & 0.198 & 1.36 & 0.046 & 0.07 \\
\hline$N$ & 0.010 & 0.39 & 0.041 & 0.42 & 0.645 & 7.70 & -0.100 & -2.70 \\
\hline \multicolumn{9}{|c|}{ Ancillary/Secondary Product } \\
\hline$m$ & $\mathcal{E}_{Y_{O}, P_{m}^{*}}$ & $t$-Stat & $\varepsilon_{Y_{N}, P_{m}^{*}}$ & $t$-Stat & & & & \\
\hline$R$ & -0.252 & -2.15 & 0.205 & 0.39 & & & & \\
\hline$F$ & 1.395 & 5.02 & 0.047 & 0.42 & & & & \\
\hline$D$ & 0.508 & 1.36 & 1.290 & 7.69 & & & & \\
\hline$S$ & 0.017 & 0.07 & -0.289 & -2.70 & & & & \\
\hline$O$ & -1.755 & -2.48 & 0.067 & -0.15 & & & & \\
\hline$N$ & 0.085 & 0.15 & -1.135 & -2.53 & & & & \\
\hline
\end{tabular}

Table 3 Product supply elasticities with respect to $\mathbf{Z}$, $\mathbf{T}$ components

\begin{tabular}{lrrrrrrrr}
\hline$x$ & \multicolumn{1}{c}{$\varepsilon_{Y_{R}, x}$} & $t$-Stat & \multicolumn{1}{c}{$\varepsilon_{Y_{F}, x}$} & \multicolumn{1}{c}{$t$-Stat } & \multicolumn{1}{c}{$\varepsilon_{Y_{D}, x}$} & $t$-Stat & $\varepsilon_{Y_{S}, x}$ & $t$-Stat \\
\hline$Z_{C}$ & $\mathbf{1 . 2 7 8}$ & 6.59 & $\mathbf{1 . 0 2 0}$ & 4.58 & $\mathbf{0 . 5 2 3}$ & 5.65 & 0.116 & 1.54 \\
$Z_{H}$ & $\mathbf{0 . 5 7 7}$ & 2.86 & -0.190 & -0.68 & $\mathbf{1 . 7 6 3}$ & 8.44 & 0.184 & 1.40 \\
$Z_{L}$ & $-\mathbf{1 . 6 3 7}$ & -5.60 & -0.060 & -0.16 & $-\mathbf{1 . 5 7 0}$ & -5.42 & -0.070 & -0.39 \\
$Z_{G}$ & 0.170 & 1.20 & 0.324 & 1.82 & -0.091 & -0.65 & $\mathbf{0 . 7 5 4}$ & 7.72 \\
$Z_{D A}$ & $-\mathbf{0 . 8 8 1}$ & -3.36 & 0.005 & 0.01 & $\mathbf{1 . 0 8 4}$ & 3.55 & 0.102 & 0.56 \\
$Z_{T O}$ & 0.316 & 1.53 & $\mathbf{1 . 2 3 8}$ & 3.81 & $\mathbf{- 0 . 7 0 8}$ & -2.84 & 0.059 & 0.44 \\
$Z_{D U}$ & $\mathbf{0 . 4 3 2}$ & 2.68 & 0.082 & 0.48 & $\mathbf{0 . 2 7 8}$ & 2.27 & 0.102 & 1.05 \\
$T_{N P I}$ & 0.098 & 0.75 & $\mathbf{1 . 0 2 1}$ & 4.51 & $\mathbf{0 . 3 7 3}$ & 2.46 & 0.043 & 0.42 \\
$T_{S W}$ & 0.106 & 1.33 & -0.223 & -1.72 & 0.041 & 0.40 & 0.058 & 0.87 \\
$T_{S A}$ & $-\mathbf{0 . 5 3 6}$ & -3.98 & -0.142 & -0.74 & -0.201 & -1.25 & 0.179 & 1.57 \\
$t$ & $\mathbf{0 . 1 2 4}$ & 8.68 & $\mathbf{0 . 1 6 0}$ & 5.51 & $\mathbf{0 . 1 0 9}$ & 5.13 & $\mathbf{0 . 0 3 7}$ & 3.43 \\
\hline
\end{tabular}

with roe close behind at 0.251 , deep-skin (high quality) fillets next at 0.176 , and regular fillets at 0.094 . For the residual products, other-pollock products have an (insignificant at 5\%) estimated marginal revenue share of 0.035 and non-pollock products have a share of 0.089 .

Marginal revenue values of all products except surimi and non-pollock products increased after the AFA. For the primary products, regular fillets comprised the lowest marginal revenue contribution in both periods, but this contribution rose significantly over time and the relative marginal share of roe became larger than that of surimi post-AFA.

For the $\mathbf{Z}$ vector components, the first-order revenue elasticities or marginal shadow shares are all significant (at 5\%) except for tow numbers. The largest (significant and positive) 


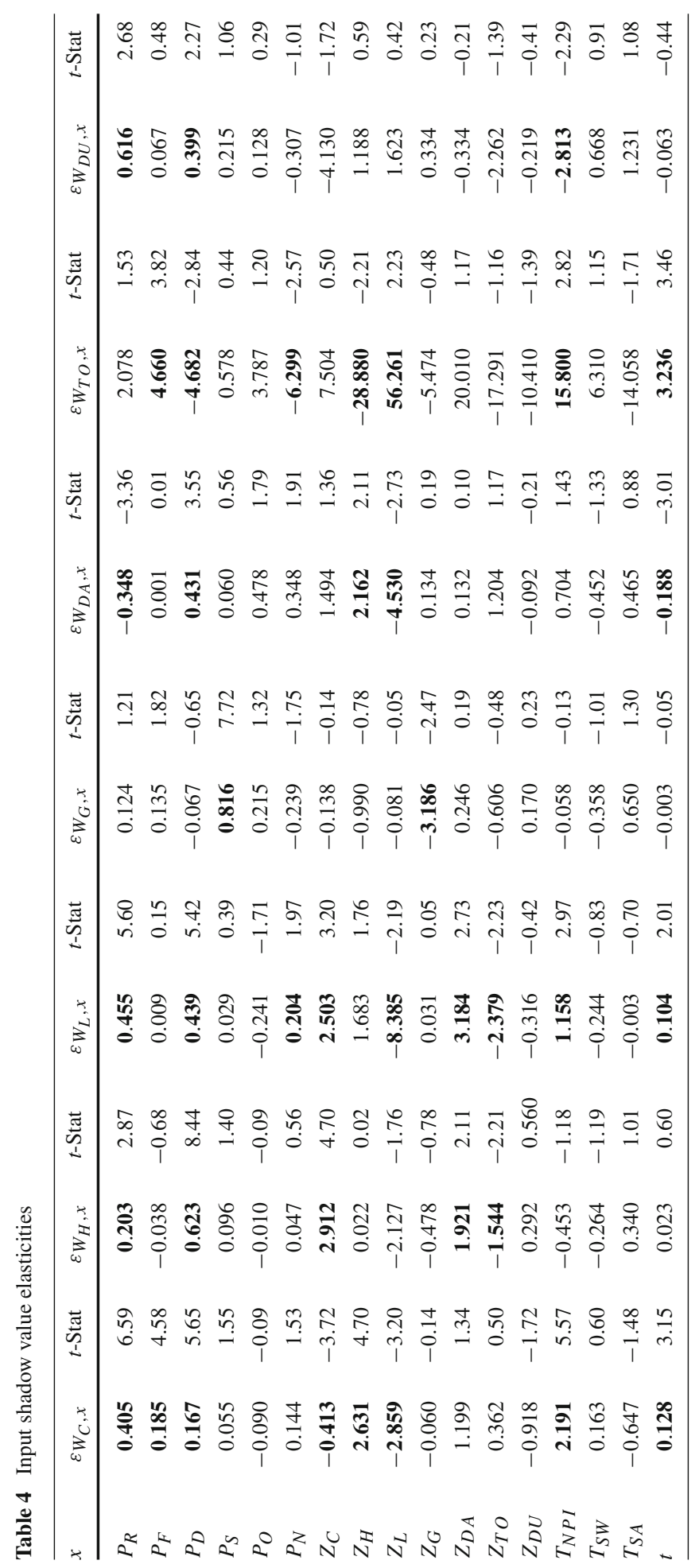


marginal revenue contribution is from crew, ${ }^{28}$ followed by the horsepower of the boat and days, and the smallest is from tow duration. By contrast, additional vessel length exhibits a negative impact on revenues, ceteris paribus, evaluated at the arithmetic mean of the data. ${ }^{29}$

However, these contributions changed significantly over time. In particular, the marginal contribution of days fell in both magnitude and significance, consistent with the move toward a longer season post-AFA as rationalization of the fishery allowed boats to increase product recovery rates in processing by their ability to slow the pace of fishing. ${ }^{30}$ That is, the high marginal value of fishing days appears to have been exploited by increasing days after the AFA eliminated the race for fish, to optimize the number of days. Similarly, tow numbers exhibited a negative revenue contribution and tow duration a positive contribution pre-AFA, but both became insignificantly positive on the margin (at the $5 \%$ level) post-AFA.

For the $\mathbf{T}$ factors, the significantly positive residual revenue time trend $\left(\varepsilon_{R t}=0.088\right.$ with a $t$-statistic of 16.0) may be interpreted as growth in economic productivity after other observed variables are taken into account. This economic productivity growth (including harvesting and processing) is nearly twice as large and more statistically significant than the productivity growth solely in terms of pollock harvest found by Felthoven et al. (2007), indicating that processing product choices have substantively contributed to the economic performance of the BSAI pollock fishery. Further, this trend is nearly twice as large (and more significant) in the post-AFA period than in the pre-AFA years. Less stormy weather also significantly augmented revenues particularly before the AFA, and (holding this atmospheric measure constant) annual temperatures affected revenues post- but not pre-AFA.

The responses of fish product supply $\left(Y_{m}\right)$ to market and other factors are represented by the second-order price elasticities in Table 2, with the own-elasticities shaded. The first sets of elasticities are for the primary products; for example, the elasticities for roe $\left(Y_{R}\right)$ supply are in the second column, with the variable with respect to which the elasticity is computed listed in the first column. The own-elasticity for $Y_{R}$ is therefore the shaded number 0.705 in the first row, with a $t$-statistic of 8.91. These elasticities are Hicksian, or input-compensated, price elasticities (Blackorby and Russell 1981), but embody product choice responses through the output cross-effects in the revenue function. The elasticities overall reflect significant ownprice responsiveness and substitutability among the primary products, which are equivalent in significance but slightly smaller in magnitude after the AFA. ${ }^{31}$

Specifically, the own-elasticities for all the primary products are positive and significant, with $Y_{F}$ the most elastic at about 2.0, indicating that a $1 \%$ increase in the price of regular fillets generates a $2 \%$ increase in their supply. Deep-skin fillets also exhibit an elastic response with an elasticity of 1.560 . Roe, with its 0.705 elasticity, and surimi with a nearly unitary elasticity at 1.030 show slightly lower (but still statistically and economically significant) price responsiveness, suggesting that other factors (such as season, vessel-specific technology, or fish quality) have a greater quantitative influence on supply of these products than for fillets.

\footnotetext{
28 For the catcher-processors in our dataset, differences in crew may be largely associated with differences in processing capability, or the size of the processing line.

29 This suggests that horsepower and tonnage better represent boat "productivity" than length. However, this is also associated with product mix; the smaller boats tend to have larger shares of deep-skin fillets (and to some extent non-pollock products) and smaller shares of surimi. The smallest boats also produce relatively less roe.

30 Specifically, slower and more precise processing can only be accomplished by slowing the rate of throughput from the harvesting activities.

31 One potential reason for this finding is that the AFA essentially guaranteed vessel owners a share of the pollock catch each year, which decreased supply uncertainty to their customers and allowed them to develop longer-term contracts for specific product forms. These longer-term production commitments may manifest themselves as diminished short-run supply responses (estimated within this model).
} 
The own-price responsiveness of both other-pollock and non-pollock products is, however, significantly negative, failing to meet the convexity conditions expected for chosen products in a revenue function. This result is consistent with their roles as residuals or secondary products for which demand rather than supply may drive this relationship (along with potential econometric identification problems for these variables). For example, boats often catch greater amounts of flatfish not due to higher flatfish prices but to factors, such as seasonal variations in the density of spawning pollock (that alter the biological/technological interactions of pollock and flatfish and affect how "cleanly" the pollock fishermen can operate). Spatial restrictions on pollock fishing, often imposed after prohibited species bycatch caps were met (particularly for salmon), can also force fishermen to fish in less desirable areas with lower pollock concentration relative to flatfish. As flatfish species have more limited markets than pollock, resulting higher flatfish supplies may drive down the prices buyers are willing to pay.

Significant supply interactions especially among the primary products are also evident, with most appearing to be substitutes (having negative cross-price elasticities). For example, regular and deep-skin fillets exhibit the most substitutability, as might be expected, with an elasticity of -2.010 of $Y_{F}$ in response to $P_{D}$ changes and -1.144 of $Y_{D}$ in response to $P_{F}$ changes. This pattern is consistent with a move in this fishery toward deep-skin fillets, due to the higher price and increased market demand for this product, although processors still shift to standard fillets when the price is right. The greatest complementary effect is also for fillets, with regular fillets being complementary to other-pollock products; a decision to produce more fillets by necessity and economy (as well as a full utilization requirement prohibiting discards of the remaining flesh after primary products have been produced) means producing more ancillary products (minced fish and fish meal) to obtain additional yield from a filleted fish. ${ }^{32}$

By comparison, the cross-supply elasticities for roe and surimi tend to be smaller in magnitude (but still statistically significant). That is, although roe production is seasonal and commands a high price, so it is standard practice for most processors to produce roe during the A season regardless of the prices of other products, there are still trade-offs. For example, the optimal time to harvest pollock for their roe may be a less than desirable time for pollock flesh (it tends to be mushy), so vessels may sacrifice roe volume if there is a price incentive to obtain more high-quality fillets. As a result, roe is substitutable to some extent with both types of fillets (the cross elasticities are significantly negative at -0.304 for regular and -0.0223 for deep-skin fillets). Further, because the flesh used to make surimi comes from the same portion of pollock used to make fillets, it is (significantly) substitutable with both kinds of fillets, and especially deep-skin fillets (with an elasticity of -0.703 relative to -0.175 for regular fillets).

Supply implications of factors in the $\mathbf{Z}$ and $\mathbf{T}$ vectors are expressed in terms of the elasticities presented in Table 3, where the columns again are the elasticities of, e.g., $Y_{R}$ (second column) with respect to the " $x$ " variables (first column). For the inputs in $\mathbf{Z}$, for example, the supply of roe is significantly positively related to crew, horsepower, and tow duration, but negatively related to vessel length and fishing days (given horsepower and tonnage). ${ }^{33}$ By contrast, surimi production is significantly (positively) related only to gross tonnage,

\footnotetext{
32 It is worth noting that this complementary pattern is also evident between deep-skin and other-pollock products, although it is smaller in magnitude and not statistically significant.

33 This does not seem to be a general relationship between roe and length, since vessels with greater length have a very similar share of roe to the average vessel. However, the negative contribution of length seems be less significant over time and for vessels of a greater length. Note also that the positive value of tons is larger and more significant in the pre-AFA than post-AFA period when these time periods are distinguished. Further, roe production is significantly positively related to tons and tow duration in the post-AFA period, although not in the pre-AFA period or overall.
} 
suggesting that holding capacity is important for surimi production (given other production characteristics).

Further, the supply of regular fillets, $Y_{F}$, is positively related to crew and especially number of tows, but the supply of deep-skin (higher-quality) fillets, $Y_{D}$, is positively related to crew, days and tow duration, and negatively related to tow numbers and vessel length. This pattern is consistent with observed post-AFA trends toward slower fishing-more days spent fishing and time spent towing - that are conducive to production of more high quality fillets. The negative dependence on the number of tows for deep-skin fillets is unexpected but stems from a significant and large (in absolute value) pre-AFA effect that becomes negligible post-AFA.

For the $\mathbf{T}$ factors, first consider the time trend, $t$. The supply of all primary products is rising significantly over time given all other measured factors, consistent with the growth in economic productivity seen from the $\varepsilon_{R t}$ measure in Table 1. Productivity growth has been highest for regular fillets, followed by roe, and the lowest for surimi. However, this productivity measure increases post-AFA in both magnitude and significance for roe and surimi, and falls slightly in size (but remains significant) for both types of fillets. ${ }^{34}$

Both types of fillets are also (significantly) positively related to $T_{N P I}$, which implies that more of these products are produced when weather is less stormy. Temperatures appear only to impact roe significantly; $Y_{R}$ is negatively related to $T_{S A}$ (but insignificantly related to $T_{S W}$ ). Roe production thus appears to be influenced more by annual than winter temperature even though roe is a winter fishery, potentially because temperature over the year has a larger impact on roe productivity and maturity rates than the temperature when the roe is processed.

Finally, we present the input shadow value elasticities in Table 4, which indicate changes in the $W_{l}$ with changes in components of the $\mathbf{P}, \mathbf{Z}$ and $\mathbf{T}$ vectors, or how processors might respond in terms of input levels or mix to changes in market or other factors. First consider the dependence of the shadow values on the prices of the fish products, which are symmetric to the estimates presented in Table 3 (as they are second-order elasticities with respect to the $\mathbf{P}$ and $\mathbf{Z}$ factors). For example, the estimates in the first row of Table 4 show that an increase in $P_{R}$ raises the shadow values of crew, horsepower, length, and tow duration, but reduces the value of days, which is the flip side of the findings from Table 3 about the impacts of inputs on roe supply. ${ }^{35}$ Similarly, a higher $P_{F}$ significantly increases only the shadow values of crew and tow numbers, whereas a higher $P_{D}$ increases the value of crew as well as $Z_{H}, Z_{L}$, $Z_{D U}$ and $Z_{D A}$, but decreases the value of tows.

Some cross-dependence is evident among the inputs; for example the shadow value of crew is positively affected by horsepower but negatively by vessel length, and the shadow values of both horsepower and length are positively impacted by more fishing days and negatively by the number of tows. The only other significant terms are own-effects; for example, more crew and greater gross tonnage appear to have a positive (from Table 1) but declining (second order) impact on revenues.

In turn, the shadow values of $Z_{C}$ and $Z_{T O}$ are increasing with $t$ (more crew and tows increase economic productivity). However, the shadow value of $Z_{D A}$ is declining, potentially due to the increase in season length (days fished) observed post-AFA, associated with slowing of production and focus on quality over quantity. Further, less stormy weather (higher $T_{N P I}$ ) increases the shadow values of crew, length, and tow numbers but decreases the value of tow duration, and changing temperatures have no significant effect on the shadow values of inputs.

\footnotetext{
34 It is worth emphasizing that as a residual measure, our technical change measure may be confounded with trends in omitted variables in our model. For example, our choice not to include a stock abundance variable directly in the function, due to its statistically insignificant impact for all specifications in preliminary analysis, implies that measured productivity change may also reflect any trends in the biological stock.

35 The effect on length is the opposite sign due to the negative shadow value of length.
} 


\section{Concluding Remarks}

In this article we use a flexible revenue function that allows consideration of interactions among all its arguments, including inputs (crew, vessel characteristics, and fishing methods) and environmental factors (weather), to evaluate production and economic performance in the BSAI pollock fishery. This rich framework results in a range of estimates reflecting the contributions of market, technological, regulatory, and environmental factors to revenue, productivity, product supply and input shadow values.

Overall, the effects of days fished and towing duration, reflecting changes in fishing methods, differ pre- and post-AFA as well as among products. In particular, increases in these factors exhibit positive and significant marginal contributions to revenue over the whole fleet, but particularly so pre-AFA.

For specific products, roe production is positively related to tow duration, potentially due to searching and testing procedures employed to find roe of the right quality and maturity before targeting a particular school of fish. Regular fillet production is positively related to the number of tows but deep-skin fillet production is negatively related to tow numbers and positively to tow duration (possibly due to decreased tow volumes in post-AFA hauls as the negative relationship becomes insignificant and the positive relationship significant post-AFA). These patterns indicate the quality implications of increasing tow numbers and duration after the AFA changed the nature of the fishery.

Further, the supply of all but one primary product (surimi) is positively and significantly related to crew size. This implies not only that crew size enhances the economic productivity of a vessel in terms of potential revenue, but also that price increases for all products but surimi increase the shadow value of crew. Days fished is, however, significantly (positively) related only to deep-skin fillet production-again likely reflecting the longer post-AFA season length combined with increased production of deep-skin fillets.

The remaining trend or "technical change" effect on revenues, controlling for factors included as arguments of our model, is strongly positive. This measure rose post-AFA and exceeds the rate of growth found in a previous study based on only harvesting productivity. Underlying this economic productivity growth we find significantly increasing supply over time for all primary products (which are strongest post-AFA with the most economically and statistically significant differences for roe and then surimi), as well as significantly increased shadow values for tows and crew.

Our results thus suggest that the improved flexibility, planning, and operational conditions under the new cooperative, quota-based BSAI fishery post-AFA enhanced its economic performance. Further, they suggest that gains associated with such a policy change have not only accrued to the harvesting sector (which has been well extolled in the literature) but also to the first-wholesale processing sector.

Acknowledgments The authors thank the National Marine Service for support and access to the data, and particularly to Terry Hiatt for help with data construction and interpretation. We also thank Clint Cummins at TSP International for his help with our econometric application, and two anonymous reviewers for their useful suggestions.

Open Access This article is distributed under the terms of the Creative Commons Attribution Noncommercial License which permits any noncommercial use, distribution, and reproduction in any medium, provided the original author(s) and source are credited.

\section{Appendix}

See Table 5 . 


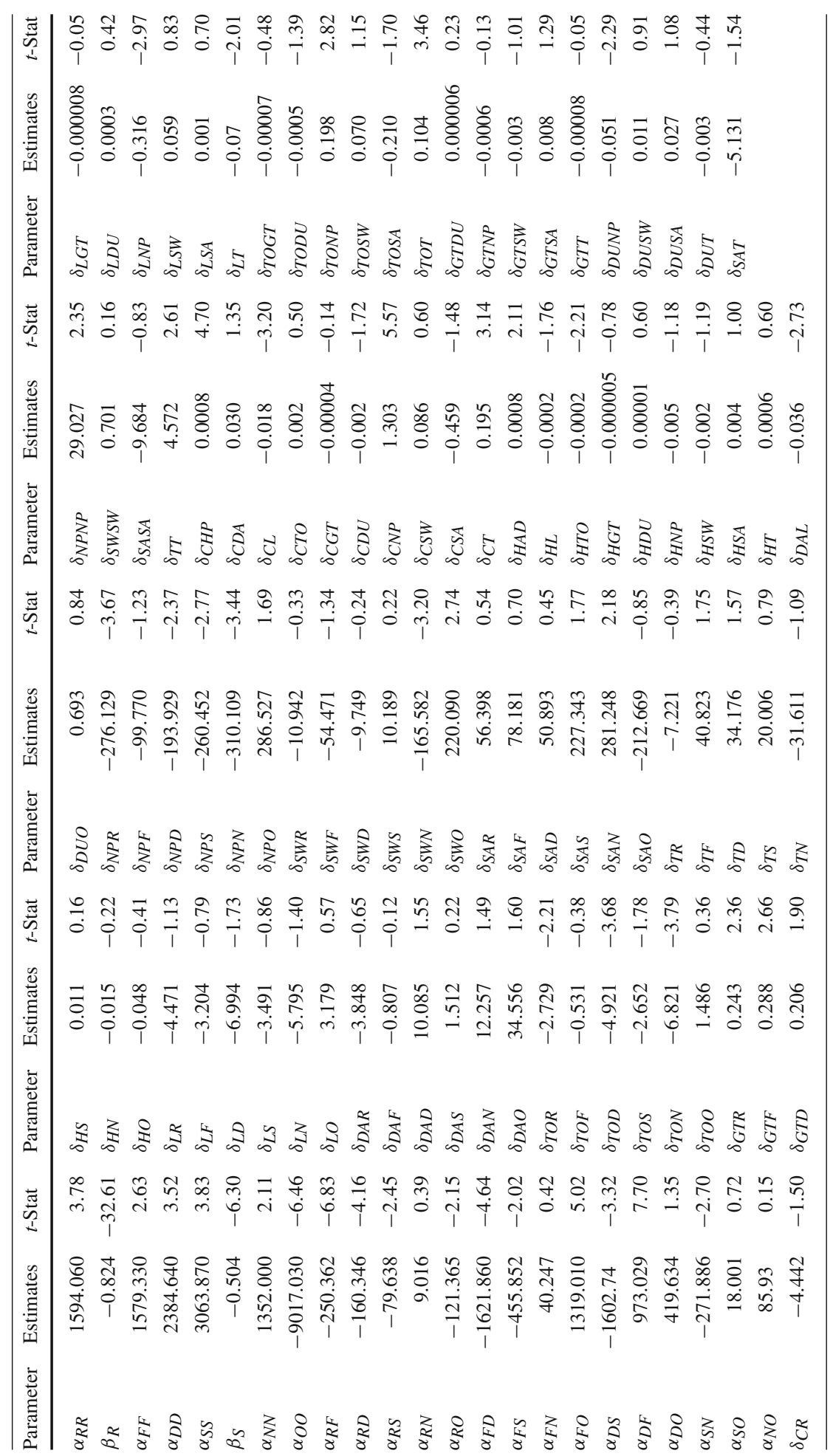




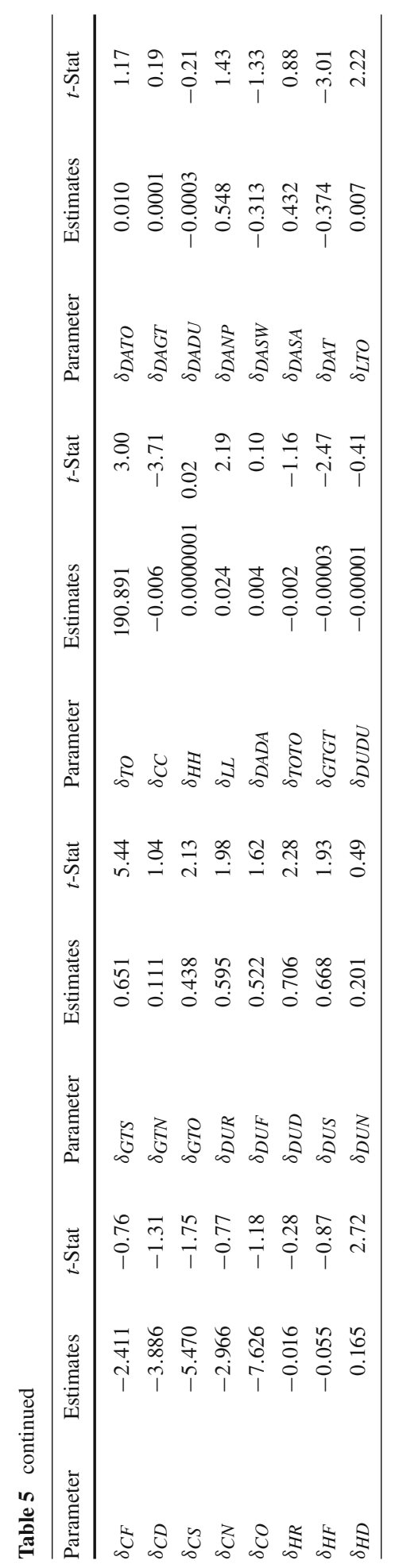




\section{References}

Alam MF, Omar IH, Squires D (2002) Sustainable fisheries development in the tropics: trawlers and license limitation in Malaysia. Appl Econ 34:325-337

Asche F, Hannesson R (2002) Allocation of fish between markets and product forms. Mar Resour Econ 17:225-238

Blackorby C, Russell R (1981) The Morishima elasticity of substitution; symmetry, constancy, separability, and its relationship to the Hicks and Allen elasticities. Rev Econ Stud 48(1):147-158

Brunt L (2007) Property rights and economic growth: evidence from a natural experiment. CEPR Discussion Papers, p 6404

Campbell HF, Nicholl RB (1994) Can purse seiners target yellowfin Tuna? Land Econ 70(3):345-354

Diop H, Kazmierczak RF (1996) Technology and management in Mauritanian Cephalopod Fisheries. Mar Resour Econ 11:71-84

Fell H (2006) Rights-based fishery management and processors supply: an application to the Alaska Pollock Fishery (manuscript). University of Washington, Washington

Felthoven RG, Morrison Paul CJ (2004) Multi-output, non-frontier primal measures of capacity and capacity utilization. Am J Agricult Econ 86(3):619-633

Felthoven RG, Morrison Paul CJ, Torres M (2007) Measuring productivity change and its components for fisheries: the case of the Alaskan Pollock Fishery, 1994-2003. Nat Resour Model

Frech H (1976) The property rights theory of the firm: empirical results from a natural experiment. J Polit Econ 84(1):143-152

Gallant AR, Holly A (1980) Statistical inference in an implicit, nonlinear, simultaneous equation model in the context of maximum likelihood estimation. Econometrica 48:697-720

Grafton Q, Squires D, Fox K (2000) Private property and economic efficiency: a study of a common-pool resource. J Law Econ 43(2):679-713

Hiatt I (2007) Stock assessment and fishery evaluation report for the groundfish fisheries of the Gulf of Alaska and Bering Sea/Aleutian Island Area: economic status of the groundfish fisheries off Alaska, 2006 National Marine Fisheries Service, Alaska Fisheries Science Center, Seattle, WA

Jensen CL (2002) Applications of dual theory in fisheries: a survey. Mar Resour Econ 17:309-334

Kirkley J, Strand I (1988) The technology and management of multi-species fisheries. Appl Econ 20: 1279-1292

Kirkley JE, Squires D, Strand I (1995) Technical efficiency in commercial fisheries. Am J Agricult Econ 77(4):686-697

NMFS (2007) Fisheries of the United States, 2007. Office of Science and Technology, National Marine Fisheries Service, Silver Spring, MD

Rausser G, Hamilton S, Kovach M, Stifter R (2008) Unintended consequences: the spillover effects of common property regulations. Department of Agricultural \& Resource Economics, UC Berkeley, Working Paper Series, p 1053

Segerson K, Squires D (1993) Capacity utilization under regulatory constraints. Rev Econ Stat 75:76-85

Segerson K, Squires D (1995) Measurement of capacity utilization for revenue-maximizing firms. Bull Econ Res 47(1):77-84

Squires D (1987) Public regulation and the structure of production in multiproduct industries: an application to the New England Otter Trawl Industry. Rand J Econ 18(2):232-248

Squires D, Kirkley J (1991) Production quota in multiproduct pacific fisheries. J Environ Econ Manag 21: $109-126$

Thunberg EM, Bresnyan EW, Adams CM (1995) Economic analysis of technical interdependencies and the value of effort in a multi-species fishery. Mar Resour Econ 10:59-76

Weninger Q (2001) An analysis of the efficient production frontier in the fishery: implications for enhanced fisheries management. Appl Econ 33:71-79

Weninger Q, Just RE (1997) An analysis of transition from limited entry to transferable quota: non-Marshallian principles for fisheries management. Nat Resour Model 10(1):53-83 